\title{
Magnetic resonance imaging in acute cervical spinal cord injury: a correlative study on spinal cord changes and 1 month motor recovery
}

\author{
NS Mahmood, R Kadavigere, AK Ramesh and VR Rao \\ Department of Radio Diagnosis and Imaging, Kasturba Medical College, Manipal, Karnataka, India
}

\begin{abstract}
Study Design: Retrospective study.
Objectives: We aimed to correlate the spinal cord changes as depicted by magnetic resonance imaging (MRI) with the neurological deficit and motor recovery of patients with acute cervical spinal cord injury $(\mathrm{SCl})$.

Setting: A total of 57 patients with acute cervical spine trauma who presented to the Department of Radio Diagnosis, Kasturba Medical College Manipal, Karnataka, India, over a period of 5 years (August 2002 to September 2007) were studied.

Methods: The pattern and extent of spinal cord changes on MRI were compared with the American Spinal Injury Association (ASIA) grade, motor index score (MIS) and the total number of useful muscles in the extremities on admission (ADM) and follow-up. The differences in the recovery rates (RR) among patients with cord edema (EDE), contusion and hemorrhage (HGE) were tested statistically.

Results: Spinal cord edema was associated with a better neurological outcome than contusion or hemorrhage, and its overall length showed a negative correlation with the recovery rate $(P=0.001)$. Conclusion: MRI is invaluable in evaluating cervical SCI. Cord edema is associated with a better neurological outcome when compared with cord contusion or hemorrhage.
\end{abstract}

Spinal Cord (2008) 46, 791-797; doi:10.1038/sc.2008.55; published online 10 June 2008

Keywords: spinal cord injuries; magnetic resonance imaging; trauma

\section{Introduction}

The cervical spine is the most common site of acute spinal injury. ${ }^{1}$ The presence of neurological deficit after cervical spinal injury suggests injury to the spinal cord and warrants further evaluation. Magnetic resonance imaging (MRI) to its inherent advantage of superior soft tissue contrast has a special role to play in the setting of acute cervical spine trauma, as it is the only modality that can reliably image the spinal cord and the soft tissues.

In animal models, the correlation of MRI with histopathology has shown that MRI provides an excellent definition of intramedullary hemorrhage and edema. ${ }^{2,9,10}$

Assessment of the spinal cord signal and morphological changes is important as it correlates well with the neurological recovery. Kulkarni et al. ${ }^{3}$ first described three basic patterns of acute spinal cord injury (SCI) on MRI (hemorrhage, contusion and edema) and correlated them with the neurological status at the time of discharge. Flanders et al., ${ }^{4}$

Correspondence: Dr NS Mahmood, Department of Radio Diagnosis and Imaging, Kasturba Medical College Manipal, Manipal, Karnataka 576104, India.

E-mail: nabilsherifmahmood@rediffmail.com

Received 10 December 2007; revised 4 May 2008; accepted 4 May 2008; published online 10 June 2008 in their study on acute cervical SCI, concluded that patients with spinal cord hemorrhage or an extensive segment of spinal cord edema at MRI would have decreased motor power, lower motor recovery rates and fewer muscles with useful function 1 year after injury in comparison with subjects with small, non-hemorrhagic lesions.

The aim of this study was to correlate the initial and final neurological status in terms of the motor scores, number of useful muscles and the recovery rate with MRI performed during the early phase of SCI to establish the prognostic implications of spinal cord changes on MRI.

\section{Materials and methods}

This was a retrospective study on patients who presented with a history of acute cervical spine trauma to the Department of Radio Diagnosis, Kasturba Medical College Manipal, India, over 5 years (August 2002 to September 2007). Cases of acute cervical spine trauma where the MRI was performed within 15 days of the onset of injury were included in the study. The following data were analyzed: the epidemiological factors such as age and sex, etiological data and clinical data such as the SCI type using the American 
Spinal Injury Association (ASIA) grade. ${ }^{6,7}$ Classification system, the upper and lower limb motor scores and the number of useful muscles in each extremity both on admission as well as on follow-up.

Magnetic resonance imaging was performed using 'SIGNA CONTOUR' of Wipro-GE Medical Systems with a superconducting $\mathrm{K} 4$ magnet of $0.5 \mathrm{~T}$ field strength.

Phased array coils were used for cervical spine with $4 \mathrm{~mm}$ slice thickness for sagittal images and $5 \mathrm{~mm}$ thickness for axial images and 240 or $280 \mathrm{~mm}$ fields of view. Sagittal T1weighted images (WI) were obtained with a spin echo (SE) sequence (TR (repetition time)/TE (echo time) $=500 / 15 \mathrm{~ms}$ ); number of excitations $(\mathrm{NEX})=3$; matrix $=256 / 224)$. Sagittal T2WIs were obtained with an SE sequence (TR/TE $=5000 /$ $100 \mathrm{~ms}$ ); $\mathrm{NEX}=3$; matrix $=256 / 224)$. Transaxial T1W SE sequences were obtained $(\mathrm{TR} / \mathrm{TE}=750 / 15 \mathrm{~ms} ; \mathrm{NEX}=4$; matrix $=256 / 192$ ). T2W transaxial images were obtained by means of a gradient recalled acquisition sequences (TR/ $\mathrm{TE}=750 / 15$; matrix $=256 / 128$; flip angle $25^{\circ}$ ).

In the evaluation of SCI, we broadened the six patterns described by Ramon et al. ${ }^{5}$

The signal changes on T1WI and T2WI with respect to the time elapsed since the trauma was used to categorize the spinal cord changes on MRI.

Normal cord

No signal abnormalities of the cord on any sequences.

\section{Spinal cord swelling}

Increase in the spinal cord caliber with no alteration in the signal intensity.

\section{Spinal cord edema}

Spinal cord edema is determined on the basis of the presence of intramedullary foci of high signal intensity on T2WIs with normal images on T1WI (Figure 1).

\section{Spinal cord contusion}

Normal images on $\mathrm{T} 1 \mathrm{~W}$, whereas on $\mathrm{T} 2 \mathrm{~W}$ the spinal cord presents with a small central area of isointensity and a thick peripheral ring of high intensity, which persists through the subacute phase (Figure 2).

\section{Spinal cord hemorrhage}

Within the first $24 \mathrm{~h}$ after spinal trauma, the cord on T1WI is heterogeneous; on T2WI, there is a large central area with low signal intensity and a thin high signal intensity peripheral rim. At $72 \mathrm{~h}$ to the first week after trauma, the spinal cord shows hyperintensity on T1W and T2W images (Figure 3).

\section{Cord compression pattern}

Severe obliteration of the spinal cord with significant alteration of its morphology preventing detection of signal alterations such as bleeding.

\section{Cord transection pattern}

Sagittal discontinuity of the spinal cord.

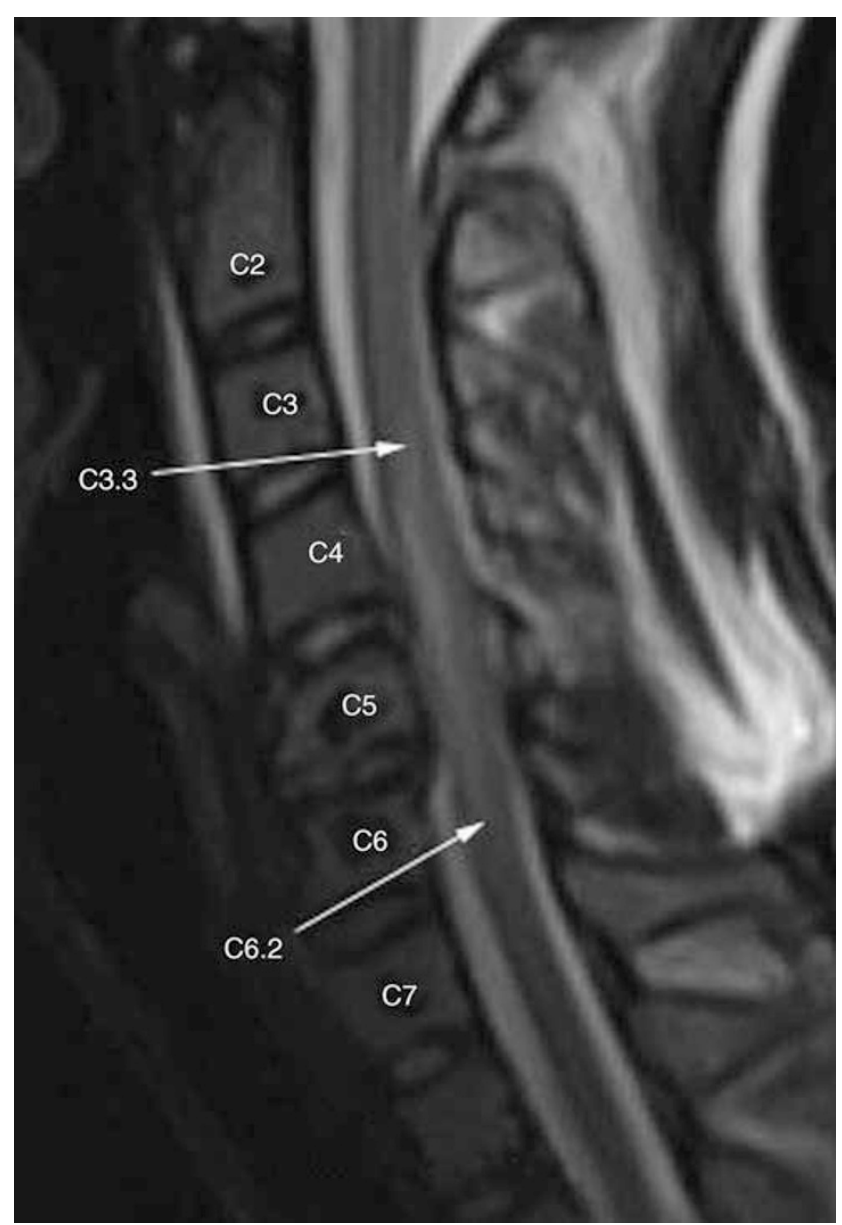

Figure 1 A 25-year-old man, who was the victim of motor vehicle accident, presented with weakness in the upper and lower limbs. He had ASIA Grade D on admission, which improved to Grade $E$ on follow-up after 1 month. A T2Wl showing uniform hyperintense intramedullary signal with extent as depicted by the arrows. The T1WI (data not shown) showed isointense cord suggestive of spinal cord edema. The rostral limit of the edema is seen at the level of the C3-C4 intervertebral disc (labeled as C3.3). The caudal limit of the edema is seen at the level of the lower segment of the C 6 vertebral body (labeled as C6.2) yielding a total length of eight segments.

Damage to the spinal cord was quantified on the midsagittal MRI images. The spinal cord signal changes and the extent of injury on MRI for each patient were tabulated by two radiologists, NSM and AKR, who were blinded to the motor scores and the recovery rates of each patient while reviewing the images.

The location of the damage to the spinal cord was quantified by locating the longitudinal boundary of the abnormality relative to the nearest adjacent spinal vertebral landmark. Each vertebral body was divided into two parts: the upper half and the lower half, segments 1 and 2, respectively. The intervertebral disk below each vertebral body was defined as segment 3 . An anatomic location was expressed as the portion of the closest vertebral body that intersected a horizontal line drawn through the lesion. Each segment location from C-2 to T-1 was rank ordered, which yielded 22 possible locations. 


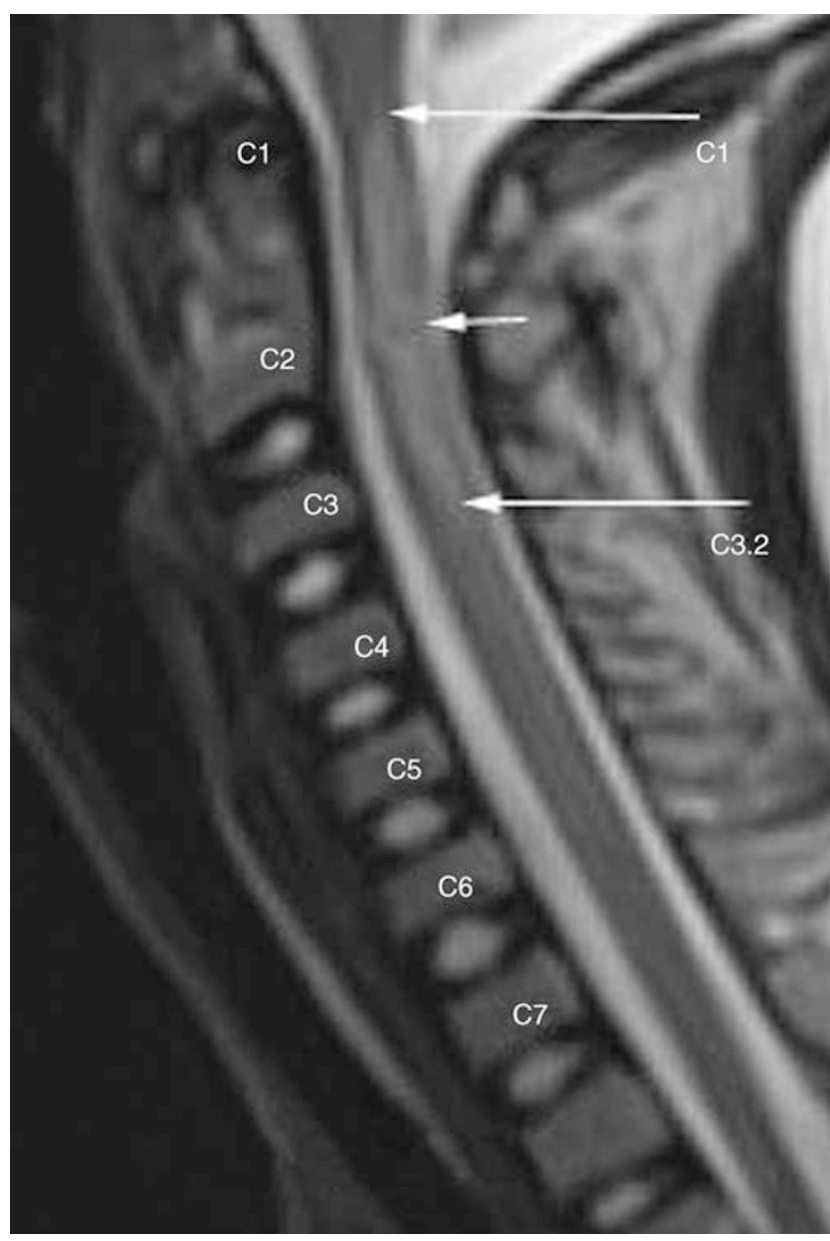

Figure 2 A 12-year-old boy with a history of fall from a height presented with Brown Sequard's syndrome. On presentation, he had Grade $C$ that improved to Grade D. The initial total motor score was 33 that improved to 45 (18\% recovery). T2WI performed 3 days after injury showing central isointense area with thick surrounding hyperintense rim suggestive of cord contusion (small white arrow) with associated spinal cord edema (extent of edema depicted by the top and bottom long white arrows). The rostral extent of the edema is seen at the level of the C1 vertebra. The caudal extent of the edema is seen at the level of the lower segment of the $C 3$ vertebral body (labeled as C3.3) yielding a total length of six segments.

The motor function, which had been assessed by physicians in the trauma center when the patient first presented, was noted from the hospital records. This had been done by testing five individual key muscles in the upper and lower extremities by using the manual muscle test. ${ }^{6}$

Each muscle received a score of $0-5$ for a total possible motor index score of 50 for the upper extremity function (five muscles measured on each side) and 50 for the lower extremity function (five muscles measured on each side).

Another measure of motor function, the number of muscles with minimally useful function, was also derived from the motor index scores. Minimally useful function in an individual muscle was defined as a score of 3 or better on the 5-point manual muscle test.

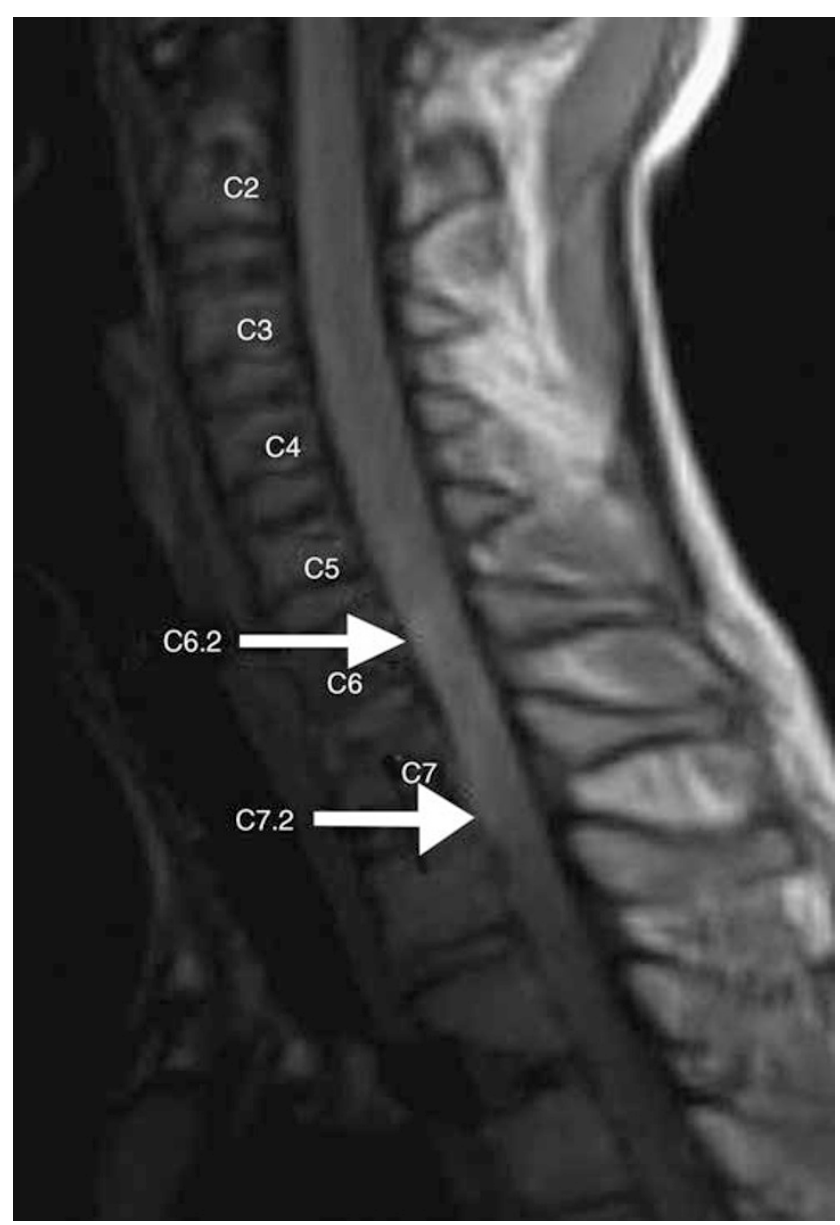

Figure 3 A 17-year-old male with a history of fall from a height presented with complete $\mathrm{SCl}$. On admission, he had Grade A on admission with no improvement on follow-up. T1WI performed 6 days after injury showing hyperintense cord signal (extent depicted by arrows) suggestive of cord hemorrhage. The rostral extent of the hemorrhage is seen at the level of the lower segment of the C6 vertebral body (labeled as C6.2) and the caudal extent at the lower segment of the C7 vertebral body (labeled as C7.2).

A score of 3 on the manual muscle test represents the ability for active movement with a full range of motion against gravity. The total number of individual muscles capable of minimally useful motor function at follow-up was compared with the number at the time of injury.

The neurological status in terms of the ASIA grade, the motor score and the number of useful muscles of each patient after 1 month (or the latest score at the time of discharge when 1 month follow-up was not available) were noted as given by the hospital records.

The motor recovery was calculated using the formula given by Lucas and Ducker: ${ }^{8}$

$$
R R=(M I S f-M I S i) /(T-M I S i)
$$

where $R R$ is the recovery rate, MISf the final motor index score, MISi the initial motor index score and $T$ the maximum possible score. 
The MIS, ASIA grade, mean useful muscles and the RR as obtained from the hospital records were then compared with the tabulated spinal cord changes and subjected to statistical analysis.

\section{Statistical methods}

All the statistical analyses and computations were performed using the software SPSS Version 10.0 for Windows.

Because spinal cord edema was seen in isolation as well as with cord contusion and hemorrhage, it was considered as an independent variable in the analysis.

The differences in the initial total motor scores, final total motor scores and the mean recovery rates between patients with spinal cord edema, contusion and hemorrhage were assessed statistically using the Kruskal-Wallis test. Spearman's correlation was used to test the relationship between the length of spinal cord edema and the recovery rate as well as the correlation between the rostral extent of the cord edema and the initial upper and lower limb motor scores. The contribution of the initial total motor scores, the rostral extent of cord edema and the total length of the cord edema to the recovery rate was tested using the regression coefficients. The statistical significance level accepted was $P \leqslant 0.05$.

\section{Statement of ethics}

None.

\section{Results}

\section{Epidemiology}

A total of 57 patients with acute SCI were included in a study of 54 men (95\%) and 3 women (5\%) with a mean age of 41 years and a s.d. of 14.7 (range 11-80) years. The most frequent cause of injury was motor vehicle accidents in 26 patients (45\%), followed by accidental fall in 23 patients (40\%).

The average time interval between trauma and imaging was 4.6 days with $95 \%$ of the patients being scanned by MRI between 3.4 and 5.8 days after trauma.

The follow-up period ranged from 2 to 30 days. The mean period of follow-up was 23 days. A total of $95 \%$ of the patients had a follow-up period that ranged between 21 and 26 days.

Table 1 Main characteristics of the sample

\begin{tabular}{|c|c|c|c|c|c|}
\hline Total number & Sex & Age (years) & $\begin{array}{l}\text { ASIA grade versus } \\
\text { number of patients }\end{array}$ & $\begin{array}{l}\text { Interval between } \\
\text { trauma and imaging (days) }\end{array}$ & $\begin{array}{l}\text { Period of follow-up } \\
\text { (days) }\end{array}$ \\
\hline 57 & $\begin{array}{l}54 \text { males } \\
3 \text { females }\end{array}$ & $\begin{array}{l}\text { Mean } 41 \\
\text { s.d. } 14.7\end{array}$ & $\begin{array}{l}\text { Grade A } 16 \\
\text { Grade B } 4 \\
\text { Grade C } 11 \\
\text { Grade D } 24 \\
\text { Grade E } 2\end{array}$ & $\begin{array}{l}\text { Mean } 4.6 \\
\text { s.d. } 4.5\end{array}$ & $\begin{array}{l}\text { Mean } 23 \\
\text { s.d. } 10.2\end{array}$ \\
\hline
\end{tabular}

Abbreviation: ASIA, American Spinal Injury Association.

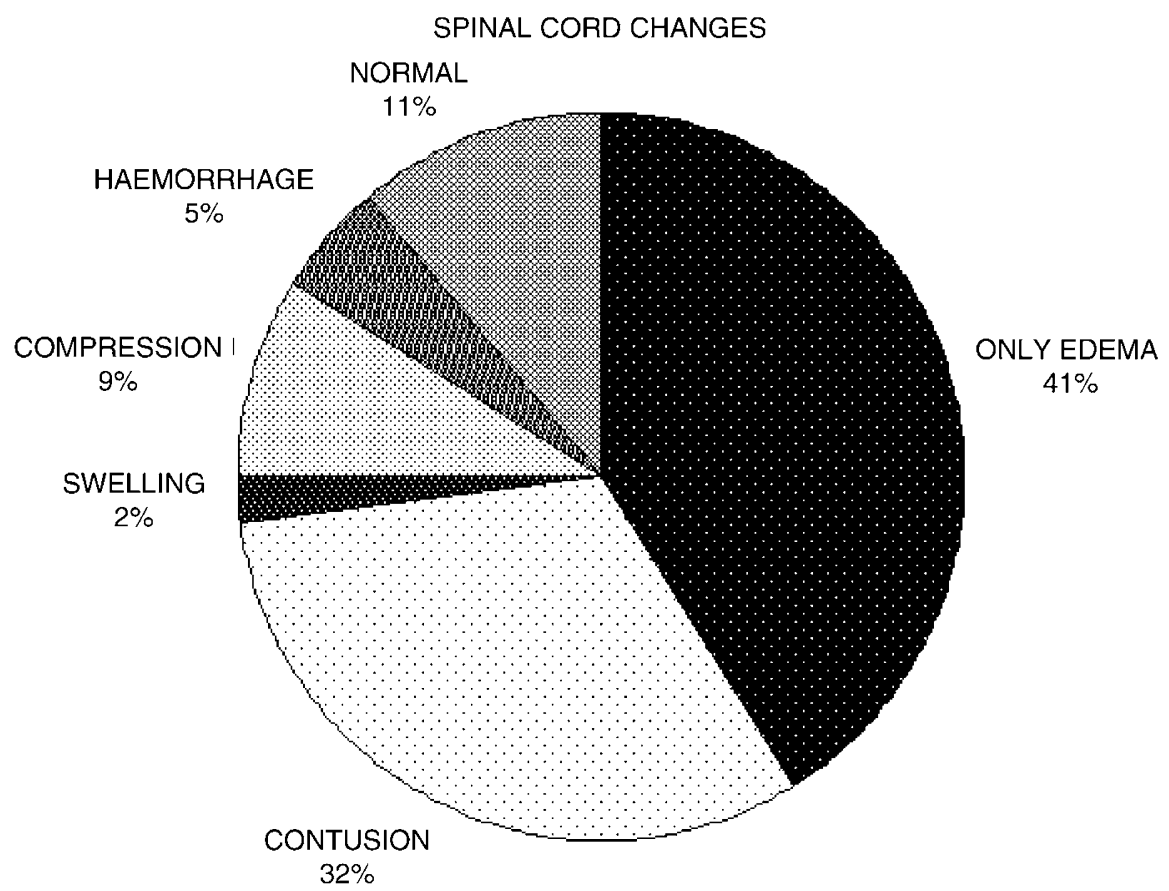

Figure 4 Spinal cord changes seen on MRI. 
Out of 57 patients, 16 had complete SCI.

In our study, spinal cord edema was the most common cord change associated with SCI (Table 1). The other cord changes that were seen are depicted in Figure 4.

Spinal cord changes and ASIA grade

The majority of patients (74\%) with spinal cord edema had Grade D on admission. In 5 patients who had Grade D on admission, MRI did not show any signal changes. However, all these patients progressed to complete recovery with Grade E on follow-up. In two patients, MRI was performed because of radiating pain after trauma, and there was no neurological deficit. The spinal cord was normal in these two cases and MRI showed only soft tissue injury.

Table 2 Grade on admission versus spinal cord changes

Grade Swelling Edema Contusion Hemorrhage Compression Normal

\begin{tabular}{lrrrrrr}
\hline A & 0 & 0 & 12 & 2 & 2 & 0 \\
B & 0 & 1 & 0 & 1 & 2 & 0 \\
C & 0 & 5 & 5 & 0 & 1 & 0 \\
D & 1 & 17 & 1 & 0 & 0 & 5 \\
E & 0 & 0 & 0 & 0 & 0 & 2 \\
\hline
\end{tabular}

The majority of patients with complete SCI (Grade A) on admission had cord contusion (75\%) with the remainder having either cord hemorrhage or cord compression (Table 2). None of the cases of spinal cord edema had complete SCI.

Spinal cord changes and motor scores

Cord edema had better upper and lower limb motor scores on admission and follow-up, when compared with those with cord contusion. The upper limb motor scores on admission were better in cord hemorrhage than those in cord contusion. However, cord hemorrhage had nil lower limb motor scores both on admission and follow-up, as all these patients had injury involving the lower cervical spine, which explains the complete loss of motor function in the lower limbs with preservation of the upper limb motor functions. The total motor scores on admission and follow-up versus the cord changes are shown in Figure 5. Cord edema had better scores when compared with contusion or hemorrhage. The difference was statistically significant $(P<0.01$ for total admission motor scores, $P<0.001$ for total follow-up motor scores).

\section{CORD CHANGES VERSUS TOTAL MOTOR SCORES}

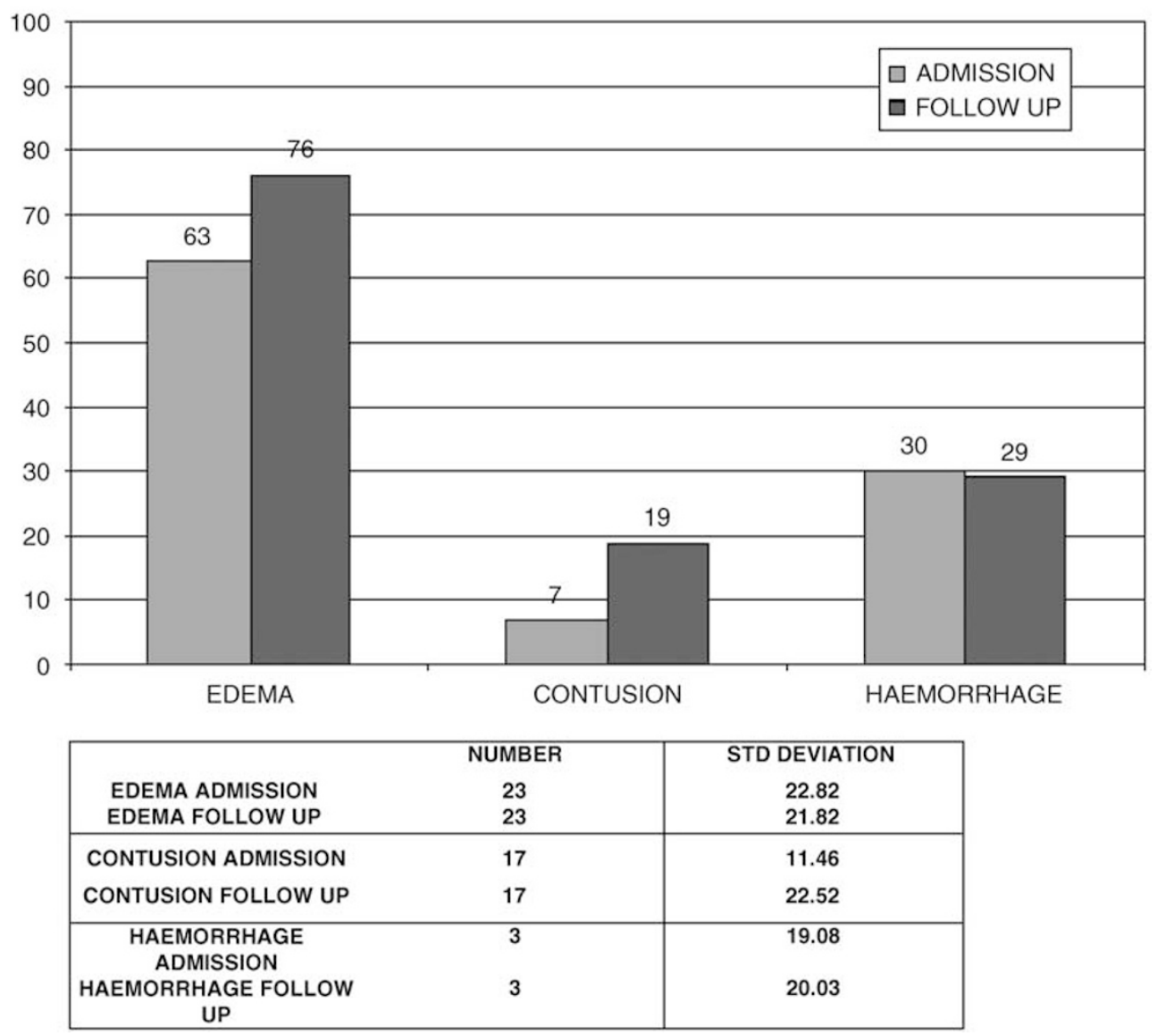

Figure 5 Total motor score on admission and follow-up versus cord changes. 
Spinal cord changes and motor recovery rate

Spinal cord edema had a significantly better recovery rate $(P<0.01)$. Spinal cord hemorrhage was associated with neurological worsening.

Spinal cord changes and mean useful muscles in the extremities The mean useful muscles on admission and follow-up in both upper limbs and lower limbs were more in cases of spinal cord edema than in those of cord contusion and hemorrhage (Figure 6). Cord hemorrhage had no useful muscles in the lower limbs both on admission and on follow-up.

Length of spinal cord edema and motor recovery rate Lengthier segments of cord edema were associated with a smaller recovery rate (correlation coefficient $r=-0.533$ ) and this was statistically significant $(P=0.001)$.

\section{Rostral extent of cord edema and upper limb motor scores on} admission

The rostral extent of cord edema showed a significant correlation with the upper limb motor index score $(P<0.05)$ such that the higher the rostral extent, the poorer was the upper limb motor score.
Factors contributing to the motor recovery rate

When the length of edema, its rostral extent and the initial total motor score were compared, it was the initial total motor score that was the most important determinant of the recovery rate $(P=0.001)$.

\section{Discussion}

Magnetic resonance imaging has a greater impact on the understanding of SCI than any other diagnostic modality. In the clinical setting, several MRI injury classification schemes have been proposed by prior investigators. ${ }^{3,11,12}$

In the evaluation of SCI, we broadened the six patterns described by Ramon et al. ${ }^{5}$ and correlated these findings with the neurological outcome.

Spinal cord edema was the most common finding. There was not a single case of spinal cord transection in our study, which by itself is quite rare in a blunt injury to the cervical spine.

Out of 57 patients, 55 had SCI in our study.

In our study, patients who showed a normal spinal cord pattern had progressed to complete neurological recovery.

Spinal cord edema was associated with better ASIA grade on admission, better initial and final total motor scores as well as mean useful muscles in the upper and lower limbs. The motor recovery rate was also significantly better in

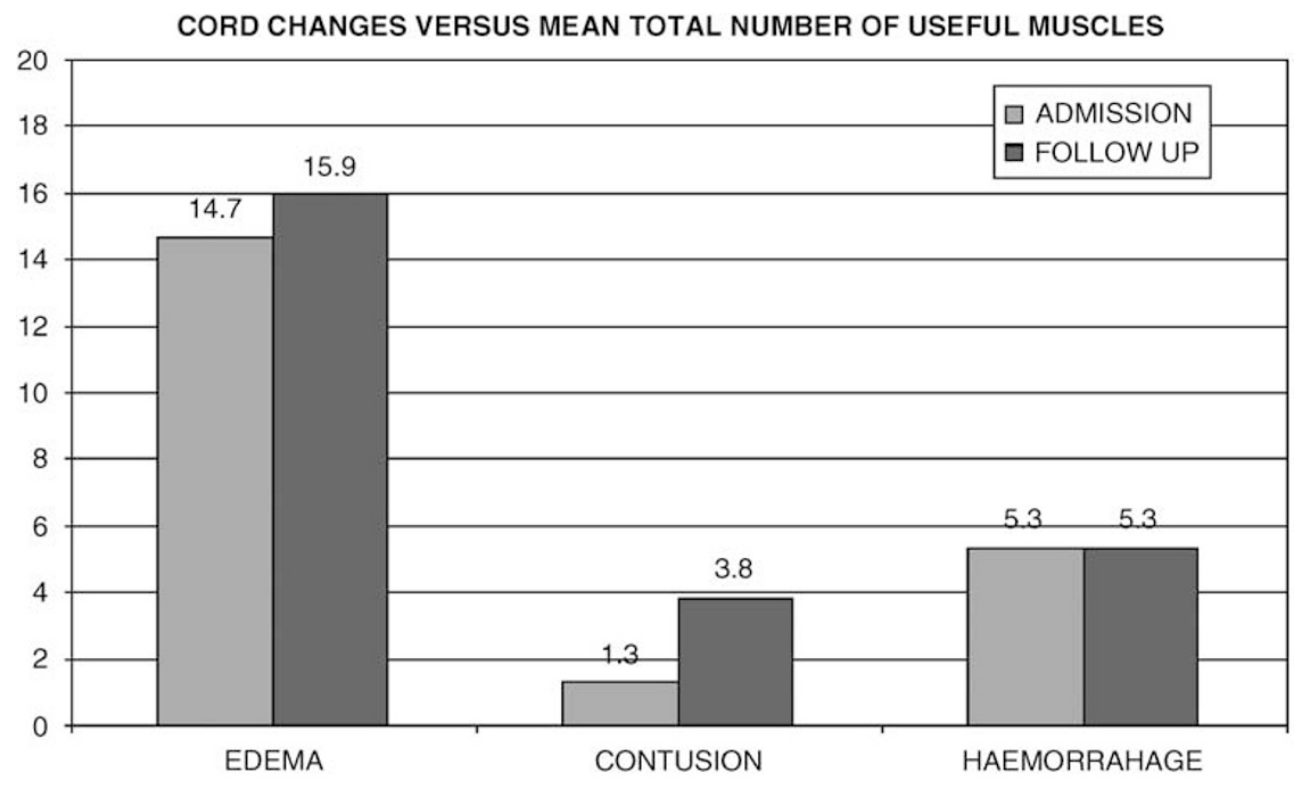

\begin{tabular}{|cc|c|}
\hline & NUMBER & STD DEVIATION \\
EDEMA ADMISSION & 23 & 5.78 \\
EDEMA FOLLOW UP & 23 & 5.33 \\
\hline CONTUSION ADMISSION & 17 & 2.76 \\
CONTUSION FOLLOW UP & 17 & 5.69 \\
\hline $\begin{array}{c}\text { HAEMORRHAGE } \\
\text { ADMISSION }\end{array}$ & 3 & 5.03 \\
$\begin{array}{c}\text { HAEMORRHAGE FOLLOW } \\
\text { UP }\end{array}$ & 3 & 5.03 \\
\hline
\end{tabular}

Figure 6 Spinal cord changes and mean useful muscles in the upper and lower limbs. 
spinal cord edema. This is in accordance with similar studies performed by other authors. ${ }^{3,13-15}$

Lengthier segments of cord edema were associated with poorer neurological outcome in our study. Flanders et al. ${ }^{16}$ had similar results in their study. Ours is the only study where the rostral extent of spinal cord edema had a significant correlation with the upper limb motor scores on admission. Flanders et al. ${ }^{4}$ were not able to establish such a correlation. This observation is significant because if it is possible to limit the spread of edema in the initial stages itself with steroids, the motor deficit can be limited. However, the role of steroids still continues to be a matter of debate.

The majority of patients with complete SCI had either cord contusion or hemorrhage. Cord hemorrhage was associated with complete loss of motor power in the lower limbs with neurological worsening.

We had only a single case of spinal cord swelling that had Grade D on both admission and follow-up. The majority of patients with cord compression had either complete SCI or Grade B on admission.

Among different factors considered, it was the initial total motor score that was the best predictor of the neurological outcome.

\section{Conclusion}

Magnetic resonance imaging is the only tool available for depicting the changes within the injured cervical spinal cord. It differentiates between spinal cord edema, contusion and hemorrhage, each of which has different prognostic implications for the patients. Cord edema is associated with a favorable neurological outcome, and its length as well as rostral extent has been shown to correlate with the recovery rates and admission motor score, respectively. Cord contusion shows a less favorable outcome. Cord hemorrhage is associated with complete SCI with poor neurological recovery.

\section{Acknowledgements}

We express our special thanks to Mr MS Kotian, statistician, Kasturba Medical College, Mangalore, India.

\section{References}

1 Kalfas I, Wilberger J, Goldberg A. Magnetic resonance imaging in acute spinal cord trauma. Neurosurgery 1988; 23: 295-299.

2 Weirich SD, Cotler HB, Narayana PA, Hazle JD, Jackson EF, Coupe $\mathrm{KJ}$ et al. Histopathologic correlation of magnetic resonance imaging signal patterns in a spinal cord injury model. Spine 1990; 15: 630-638.

3 Kulkarni MV, McArdle CB, Kopanicky D, Miner M, Cotler HB, Lee KF et al. Acute spinal cord injury: MRI imaging at 1.5 T. Radiology 1987; 164: 837-843.

4 Flanders AE, Spettell CM, Tartaglino LM, Friedman DP, Herbison GJ. Forecasting motor recovery after cervical spinal cord injury: value of MR imaging. Radiology 1996; 201: 649-655.

5 Ramon S, Domínguez R, Ramírez L, Paraira M, Olona M, Castelló $\mathrm{T}$ et al. Clinical and magnetic resonance imaging correlation in acute spinal cord injury. Spinal Cord 1997; 35: 664-673.

6 American Spinal Injury Association, International Medical Society of Paraplegia (ASIA/IMSOP). International Standards for Neurological and Functional Classification of Spinal Cord Injury. Revised 1992. American Spinal Injury Association: Chicago, IL, 1992.

7 Ditunno JF, Young W, Donovan WH, Creasy G. The international standards booklet for neurological and functional classification of spinal cord injury. Paraplegia 1994; 32: 70-80.

8 Lucas JT, Ducker TB. Motor classification of spinal cord injuries with mobility, morbidity and recovery indices. Am Surg 1979; 45: 151-158.

9 Perovitch M, Perl S, Wang H. Current advances in magnetic resonance imaging (MRI) in spinal cord trauma: review article. Paraplegia 1992; 30: 305-316.

10 Hackney DB, Asato LR, Joseph P, Carvlin MJ, McGrath JT, Grossman RI et al. Hemorrhage and edema in acute spinal cord compression: demonstration by MRI imaging. Radiology 1986; 161: 387-390.

11 Wittenberg RH, Boetel U, Beyer HK. Magnetic resonance imaging and computed tomography of acute spinal cord trauma. Clin Orthop 1990; 260: 176-185.

12 Chakeres DW, Flickinger F, Bresnahan JC, Beattie MS, Weiss KL, Miller $\mathrm{C}$ et al. MRI imaging of acute spinal cord trauma. Am J Neuroradiol 1987; 8: 5-10.

13 Marciello MA, Flanders AE, Herbison GJ, Schaefer DM, Friedman $\mathrm{DP}$, Lane JI et al. Magnetic resonance imaging related to neurologic outcome in cervical spinal cord injury. Arch Phys Med Rehabil 1993; 74: 940-946.

14 Cotler HB, Kulkarni MV, Bondurant FJ. Magnetic resonance imaging of acute spinal cord trauma: preliminary report. J Orthop Trauma 1988; 2: 1-4.

15 Kulkarni MV, Bondurant FJ, Rose SL, Narayana PA. 1.5 Tesla magnetic resonance imaging of acute spinal trauma. Radiographics 1988; 8: 1059-1082.

16 Flanders AE, Schaefer DM, Doan HT, Mishkin MM, Gonzalez CF, Northrup BE et al. Acute cervical spine trauma: correlation with degree of neurological deficit. Radiology 1990; 177: 25-33. 